\title{
Media Quiet Book untuk Meningkatkan Keterampilan Merawat Luka Ringan Anak Tunagrahita
}

\author{
Gema Siam Sari, Abdul Huda, Usep Kustiawan \\ Universitas Negeri Malang \\ E-mail: pugud.gema@gmail.com
}

\begin{abstract}
Abstrak: Keefektifan Media Quiet Book untuk Meningkatkan Keterampilan Merawat Luka Ringan Bagi Anak Tunagrahita. Tujuan dilakukan penelitian ini adalah utnuk mengetahui tingkat keefektifan media quiet book untuk meningkatkan keterampilan merawat luka ringan bagi anak tunagrahita dengan mengadaptasi metode pengembangan Borg and Gall yang memiliki sepuluh tahap, namun dalam penelitian ini hanya mengadaptasi tujuh langkah. Hasil pengembangan produk media quiet book secara keseluruhan dapat disimpulkan bahwa media quiet book efektif digunakan untuk meningkatkan keterampilan merawat luka ringan bagi anak tunagrahita ringan.

Kata Kunci : Keterampilan Merawat Luka Ringan, Media Quiet Book, Tunagrahita Ringan
\end{abstract}

\begin{abstract}
The Effectiveness of Media Quiet Book to Improve Skills for Caring for Mild Wounds for Children with intelectual disability. Books for improving the development of methods for treating minor injuries for adapting the development method of Borg and Gall which have ten stages, but in this study only adapted seven steps. The overall results of the development of quiet media products can be concluded that effective books are used to improve the skills of treating minor injuries for mild mentally retarded children.
\end{abstract}

Keywords: Mild Wound Care, Media Quiet Book, Mild Intellectual Disability

Undang Undang Dasar 1945 pasal 31 ayat 1 menyebutkan bahwa "Setiap warga negara berhak mendapat pendidikan." dan Undang-Undang Nomor 20 pasal 4 tahun 2003 tentang Sistem Pendidikan Nasional menyebutkan juga bahwa "Pendidikan diselenggarakan secara demokratis dan berkeadilan serta tidak diskriminatif dengan menjunjung tinggi hak asasi manusia, nilai keagamaan, nilai kultural, dan kemajemukan bangsa".

Pendidikan menurut Undang-Undang No.20 tahun 2003 adalah suatu usaha sadar dan terncana untuk mewujudkan suasana belajar dan proses pembelajaran agar peserta didik secara aktif mengembangkan potensi dirinya untuk memiliki kekuatan spiritual keagamaan, pengendalian diri, kepribadian, kecerdasan, akhlak mulia, serta keterampilan yang diperlukan dirinya, masyarakat, bangsa dan negara. Pendidikan menjadi suatu cara untuk meningkatkan potensi siswa. Penelitian pendahulu dilakukan observasi di SDLB B-C Kepanjen pada tahun 2019 awal dengan menganalisis kebutuhan sekolah dan mengumpulkan data mengenai kegiatan bina diri. Hasil analisis kebutuhan, diperoleh data mengenai tidak adanya media yang dapat digunakan untuk mempelajari keterampilan merawat luka ringan untuk anak tunagrahita. Selama ini disekolah hanya memperlajari dan melatih bina diri seperti memakai sepatu, mengancing baju, toiletris, tanpa ada menolong diri seperti merawat luka ringan. Anak dengan hambatan intelektual adalah salah satu dari beberapa klasifikasi dari anak berkebutuhan khusus. Menurut American Psychiactric Association (APA, 2013) menuliskan bahwa gangguan perkembangan adalah gangguan yang terjadi selama periode perkembangan, yang mencakup kurangnya fungsi intelektual dan fungsi adaptif dalam konseptual, sosial dan taktis. Perkembangan fungsi intelektual anak tunagrahita yang rendah dan disertai dengan perkembangan perilaku adaptif yang rendah pula akan berakibat langsung pada kehidupan seharihari, sehingga ia banyak mengalami kesulitan dalam hidupnya. Masalah-masalah yang dihadapi tersebut secara umum ialah : (1) masalah belajar; (2) masalah penyesuaian diri; (3) gangguan bicara dan bahasa; (4) masalah kepribadian yang dikemukakan oleh Rochyadi (2005) dalam Apriyanto (2012). Tunagrahita adalah individu yang memiliki intelegensi yang signifikan berada dibawah rata-rata dan disertai dengan ketidakmampuan dalam adaptasi perilaku yang muncul masa perkembangan, pembelajaran bagi tunagrahita lebih dititik beratkan pada kemampuan bina diri dan sosialisasi (Meimulyani \& Caryoto, 2013)

Anak tunagrahita perlu diberikan pelayanan khusus untuk menumbuhkan dan mengembangkan potensi dan kemampuannya seoptima mungkin. Bina diri adalah kegiatan latihan yang dilakukan guru kepada individu agara melakukan aktivitas tanpa bergantung pada orang lain. Mumpuniarti (dalam Basuni, 2012) mengemukakan program bina diri merupakan program yang dipersiapkan agar siswa dengan hambatan mental mampu menolong diri sendiri dalam bidang yang berkaitan untuk kebutuhan dirinya sendiri. Salah satu kemampuan bina diri yang perlu ditingkatkan yaitu kegiatan menolong diri. Keterampilan menolong diri adalah sutau keterampilan yang memungkinkan anak berkebutuhan khusus dapat mencapa kehidupan yang 
lebih mandiri. Keterampilan menolong diri adalah keterampilan menghindar atau mengendalikan diri dari bahaya (Widati, 2011. dalam modul Bina Diri Bagi Anak Berkebutuhan Khusus).

Penggunaan media pembelajaran merupakan hal yang sangat penting dalam mengajar anak tunagrahita. National Education Assosiation (NEA) mendefinisikan sebagai benda yang dapat dimanipulasi, dilihat, didengar, dibaca atau dibicarakan beserta instrument yang dipergunakan dengan baik dalam kegiatan belajar mengajar, dapat mempegaruhi efektivitas program instruksional. Media quiet book adalah salah satu media yang diduga lebih sesuai dengan karakteristik anak, digunakan utuk mengembangkan keterampilan merawat luka ringan, sehingga nantinya anak mampu mengikuti proses pembelajaran mejadi lebih baik.

Media quiet book dapat memberikan visualisasi cerita yang lebih menarik, memiliki tampilan gambar yang terlihat berdimensi, gambar dapat timbul serta memiliki objek 3 dimensi yang dapat dimainkan oleh anak. Quiet book digemari karena keunikannya dan kelebihannya seperti bentuk fisik yang empuk dan lembut, tidak gampang sobek dan dapat dicuci. Quiet Book dalam artikel yang dimuat oleh website QuietBook Queen and Craft In Between adalah terbuat dari kain dan dijahit bersama, setiap halamannya berfungsi sebagai : a) keterampilan motorik halus seperti mengikat tali sepatu, mengepang, menutup resleting, dll; b) keterampilan kognitif seperti menghitung, membuat kata, mengidentifikasi warna dan bentuk; c) imaginasi dan bermain peran seperti menelefon, menyikat gigi, belanja dan melukis.

Tujuan penelitian pengembangan ini adalah menghasilkan media quiet book yang efektif dan layak untuk meningkatkan keterampilan menolong diri merawat luka ringan bagi anak tungrahita ringan di kelas VI SDLB B-C Kepanjen Kabupaten Malang. Dalam penelitian ini dikembangkan media quiet book berupa lembaran-lembaran kain berbahan utama kain katun dan kain flanel yang diletakkan gambar-gambar atau simbol lain yang mempunyai unsur 3 dimensi tentang kegiatan keterampilan merawat luka ringan. Anak juga akan bermain peran menjadi dokter dan belajar bagaimana merawat luka dengan baik dan benar. Menampilkan corak warna yang mencolok, sehingga anak akan tertarik untuk memainkannya.

\section{METODE}

Tujuan penelitian ini adalah mengukur tingkat keefektifan media quiet book untuk meningkatkan keterampilan menolong diri merawat luka ringan bagi anak tungrahita ringan di kelas VI SDLB B-C Kepanjen Kabupaten Malang. Mengacu pada pendekatan Research \& Development (R\&D) dari Borg and Gall (Silalahi, 2017).

Berikut ini merupakan langkah-langkah rancangan dari Borg and Gall : (1) Research and Information collecting; (2) Planning; (3) Develop Preliminary From a Product; (4) Preliminary Field Testing; (5) Main Product Revision; (6) Main Field Testing; (7) Operational Product Revision; (8) Operational Field Testing; (9) Final Product Revision; (10) Dissemination and Implementation. Peneliti menggunakan 7 langkah dari 10 langkah model pengambangan research and development $(\mathrm{R} \& \mathrm{D})$ dari Borg and Gall. Pemilihan 7 langkah tersebut telah mempertimbangkan karakteristik yang akan diteliti dan keterbatasan waktu, tenaga serta biaya yang dimiliki peneliti Langkah-langkah model research and development yang digunakan dalam penelitian ini yaitu: (1) Research and Information collecting; (2) Planning; (3) Develop Preliminary From a Product; (4) Preliminary Field Testing; (5) Main Product Revision; (6) Main Field Testing; (7) Final Product Revision;

Subjek uji coba yang terlibat dalam penelitian ini ialah siswa tunagrahita SDLB di SLB B-C Kepanjen Malang. Uji coba dilakukan dengan 2 tahap, yang pertama uji coba individu dilakukan oleh satu siswa tunagrahita, dan uji coba kelompok dengan jumlah subjek 2 siswa tunagrahita.

Instrumen yang digunakan dalam penelitian ini adalah tes kinerja diguakan untuk mengukur tingkat kemampuan siswa pada kegiatan merawat luka ringan dan termasuk ranah praktik yang diikutkan pada ranah pengetahuan secara lisan.

Pengumpulan data dilakukan dengan 3 tahap, yaitu: 1) pre-test yang dilakukan sebanyak satu kali pada setiap tes, guna untuk mengetahui kemampuan awal siswa, 2) treatment yang dilakukan sebanyak tiga kali oleh peneliti guna memberi latihan untuk merawat luka ringan. 3) post-test dilakukan sekali tiap test guna mengetahui kemampuan setelah dilakukan treatment. Teknik analisis data menggunakan analisis data kuantitatif dan kualitatif. Teknik analisis data yang digunakan dalam penelitian ini adalah kualitatif dan kuantitatif. Data kualitatif berupa hasil observasi dan teknik kuantitatif digunakan untuk menghitung skor tes kinerja yang diadopsi oleh Arikunto (2013) .

\section{HASIL DAN PEMBAHASAN}

\section{Hasil}

Hasil analisis data diperoleh hasil uji coba individu pretest dengan nilai $36 \%$ dalam kriteria evaluasi subjek uji coba dapat dikatakan rendah atau tidak efektif. Setelah dilakukan pretest tanpa menggunakan media quiet book, siswa kemudian menggunakan media quiet book dalam kegiatan pembelajaran merawat luka ringan. Kemudian dilkukan post-test, memperoleh hasil uji coba individu dengan nilai $96 \%$ dalam kriteria evaluasi subjek uji coba maka dikatakan sangat tinngi, sangat efektif. 
Tabel 1. Rekapitulasi skor hasil uji coba

\begin{tabular}{cccccc}
\hline \multirow{2}{*}{ No. } & Nama & \multicolumn{4}{c}{ Skor } \\
\cline { 3 - 6 } & & Pretest & Ket. & Posttest & Ket. \\
\hline 1. & PTR & $36 \%$ & Rendah & $96 \%$ & $\begin{array}{l}\text { Sangat } \\
\text { Tinggi }\end{array}$ \\
\hline 2. & FY & $36 \%$ & Rendah & $89 \%$ & $\begin{array}{c}\text { Sangat } \\
\text { Tinggi }\end{array}$ \\
\hline 3. & AD & $48 \%$ & $\begin{array}{c}\text { Kurang } \\
\text { Tinggi }\end{array}$ & $93 \%$ & $\begin{array}{c}\text { Sangat } \\
\text { Tinggi }\end{array}$ \\
\hline Rata-Rata & $\mathbf{4 0 \%}$ & Rendah & $\mathbf{9 3 \%}$ & $\begin{array}{c}\text { Sangat } \\
\text { Tinggi/ } \\
\text { Sangat } \\
\text { Efektif }\end{array}$ \\
\hline
\end{tabular}

Tabel. 2 Tahapan Yang Mudah dan Sulit Dilakukan Oleh Siswa

\begin{tabular}{|c|c|}
\hline $\begin{array}{l}\text { Tahapan yang mudah } \\
\text { dilakukan oleh siswa }\end{array}$ & $\begin{array}{l}\text { Tahapan yang sulit } \\
\text { dilakukan oleh siswa }\end{array}$ \\
\hline $\begin{array}{l}\text { - Mencuci luka } \\
\text { menggunakan air atau } \\
\text { cairan antiseptik }\end{array}$ & $\begin{array}{l}\text { - Mengeringkan luka } \\
\text { sampai benar - benar } \\
\text { kering }\end{array}$ \\
\hline $\begin{array}{l}\text { - Mengolesi luka dengan } \\
\text { betadine atau obat merah }\end{array}$ & $\begin{array}{l}\text { - Mengompres luka } \\
\text { dengan air es pada } \\
\text { bagian tubuh yang }\end{array}$ \\
\hline $\begin{array}{l}\text { - Mengolesi luka dengan } \\
\text { krem atau salep }\end{array}$ & $\begin{array}{l}\text { - Membalut luka dan } \\
\text { memberi penekanan }\end{array}$ \\
\hline $\begin{array}{l}\text { - Menutup luka dengan } \\
\text { menggunakan plaster }\end{array}$ & $\begin{array}{l}\text { - Merendam pada air } \\
\text { dingin }\end{array}$ \\
\hline
\end{tabular}

Dari data tersebut jika dilihat dari kriteria evaluasi subjek uji coba lapangan, dikatakan sangat tinggi, dan media quiet book dapat digunakan dan sangat efektif untuk meningkatkan keterampilan merawat luka ringan bagi anak tunagrahita ringan. hasil uji coba kelompok dengan nilai rata-rata pretest sebelum menggunakan media quiet book memperoleh nilai rata-rata $42 \%$ menurut kriteria evalusi subjek uji coba lapangan dikategorikan kurang tinggi. Sedangkan posstest hasil uji coba kelompok setelah menggunakan media quiet book dalam kegiatan pembelajaran merawat luka ringan diperoleh nilai rata-rata sebesar 91\% menurut kriteria evaluasi subjek uji coba lapangan hasil tersebut dapat dikatakan sangat tinggi, sangat efektif. Dari data tersebut dapat disimpulkan bahwa media quiet book sangat efektif untuk digunakan dalam meningkatkan keterampilan merawat luka ringan bagi anak tunagrahita.

Hasil uji coba yang dilakukan secara individu dan kelompok, terdapat kenaikan nilai yang didapatkan siswa dari hasil belajar dari sebelum hingga sesudah menggunakan media quiet book merawat luka ringan. Keseluruhan siswa mendapatkan nilai diatas kriteria tingkat presentase evaluasi subjek uji coba. Maka media quiet book sangat efektif dan dapat digunakan sebagai media pembelajaran yang berfungsi untuk meningkatkan keterampilan merawat luka ringan bagi anak tunagrahita ringan kelas VI di SDLB B-C Kepanjen Kabupaten Malang secara individu maupun kelompok.

\section{Pembahasan}

Media quiet book untuk meningkatkan keterampilan merawat luka ringan merupakan media yang digunakan sesuai dengan karakteristik siswa tunagrahita ringan. Media quiet book ini dibuat semenarik mungkin sehingga dapat digunakan secara bebas dan praktis serta mudah untuk dipahami oleh siswa tunagrahita ringan. Media quiet book ini dibuat menggunakan perpaduan bahan kain katun dan kain flanel dengan warna-warna yang cerah dan terdapat gambar-gambar yang menarik. Hal tersebut bertujuan untuk memberi daya tarik dan minat bagi siswa tunagrahita ringan untuk mempelajari materi tentang kegiatan keterampilan merawat luka ringan. Media ini bersifat interaktif yang didalamnya berisi halamanhalaman bergambar dan huruf yang dapat dilepas pasang dan juga dimainkan sendiri. Bentuk tampilan ini juga didukung dan dilengkapi teks narasi singkat yang menceritakan kronologi mendapatkan luka ringan. Produk ini dikemas dalam bentuk buku kain yang menarik dilengkapi dengan tas penyimpanan.

Media quiet book sering juga disebut busy book / activities book, yaitu media 3 dimensi jenis model tiruan berupa buku kain yang menggunakan materian jenis kain flanel dan kain katun, terdiri dari halamanhalaman yang berisi bermacam-macam kegiatan anakanak seperti menghitung, mengenal warna, mengikat tali, mengenal satwa, melakukan tugas rumah seharihari, dll yang bersifat edukatif. Quiet Book dalam artikel yang dimuat oleh website QuietBook Queen and Craft In Between adalah terbuat dari kain dan dijahit bersama, setiap halamannya berfungsi sebagai : a) keterampilan motorik halus seperti mengikat tali sepatu, mengepang, menutup resleting, dll; b) keterampilan kognitif seperti menghitung, membuat kata, mengidentifikasi warna dan bentuk; c) imaginasi dan bermain peran seperti menelefon, menyikat gigi, belanja dan melukis. Pada pengembangan yang dilakukan oleh peneliti mengembangkan media quiet book untuk meningkatkan keterampilan merawat luka ringan yang juga meliputi : a) keterampilan motorik seperti membaluk luka menggunakan plaster atau perban; b) keterampilan kognitif seperti menyusun kata 'ambulans','dokter', dan 'perawat'; c) imajinasi dan bermain peran seperti berperan menjadi dokter atau perawat. Quiet book menekankan aktifitas yang berhungan dengan keterampilan misalkan mencocokkan, menyortir, bermain peran, dan memakai pakaian sendiri. Di setiap halaman quiet book terdapat gambar-gambar kucu yang bisa dipasang, dibuka, ditempel, atau dipasangkan dari tema setiap gambar 
(Ramadhani dan Sudarsini, 2018). Pengembangan yang dilakukan peneliti media quiet book mengembangkan pada merawat luka ringan tidak hanya bisa dipasang, dibuka, ditempel, atau dipasangkan dari tema setiap gambar, tetapi juga dapat dimainkan, seperti membalut luka, mencuci luka, mengompres luka sesuai tema masing-masing halaman.

Media quiet book berisi materi tentang tahaptahap merawat luka ringan seperti luka lecet, luka memar, luka sayat dan luka bakar. Dari tahap-tahap tersebut setelah diuji coba pada siswa, terdapat tahaptahap yang mudah dan sulit dilakukan atau dipraktikkan oleh siswa. Adapun paparan dapat dilihat pada tabel

2. Dari berbagai langkah tersebut terdapat tahapan yang sulit untuk dilakukan oleh siswa, maka dari itu cara yang dapat digunakan untuk mengajarkan siswa adalah dengan menjelaskan dan mempraktikkan setiap tahapan secara berulang-ulang, teratur, dan berurutan agar mampu dipahami. Hal tersebut dilakukan agar mereka mampu menguasai keterampilan merawat luka ringan.

Berdasarkan penelitian yang telah dilakukan terdapat beberapa temuan saat mengamati penelitian. Pada saat pretest siswa tidak mengetahui nama-nama peralatan $\mathrm{P} 3 \mathrm{~K}$ yang digunakan untuk merawat luka. Bahkan tidak mengetahui bagaimana merawat luka ringan. Pada langkah mencuci luka hingga bersih, siswa cenderung mencuci luka dengan asal sehingga luka yang dicuci tidak bersih sempurna. Selanjutnya pada pemberian plaster atau perban, siswa banyak melewatkan langkah tersebut. Jadi setelah dilakukan pemberian obat merah, siswa hanya membiarkan luka tersebut tanpa diberi plaster. Pada luka bakar, siswa tidak mengetahui bagaimana tahap merawat luka bakar dengan benar, siswa hanya mengetahui hanya mencuci lukanya saja, tanpa tahu adanya perawatan selanjutnya seperti mengompres menggunakan air, membalut luka pada bagian luka. Setelah dilakukan treatmen siswa mengetahui masing-masing nama isi kotak P3K. Memahami tahapan-tahapan merawat luka ringan seperti luka sayat, memar, bakar, dan lecet.

Kemudian terdapat beberapa temuan selama melakukan kegiatan post-test diantaranya siswa yaitu siswa mampu melakukan dengan mandiri, seperti mencuci luka dengan bersih secara mandiri. Kemudian memberi betadine atau obat merah. Siswa memahami setiap tahapan merawat luka dengan baik dan benar, tanpa ada yang terlewat.

\section{KESIMPULAN DAN SARAN}

\section{Kesimpulan}

Media quiet book dapat disimpulkan sebagai berikut: 1) media quiet book untuk meningkatkan keterampilan merawat luka ringan bagi anak tunagrahita kelas VI di SDLB B-C Kepanjen Kaupaten Malang dinyatakan memiliki kemenarikan, kemudahan. (2) Berdasarkan hasil uji coba dapat disimpulkan bahwa produk media quiet book untuk meningkatkan keterampilan merawat luka ringan bagi anak tunagrahita kelas VI di SDLB B-C Kepanjen Kaupaten Malang, efektif dapat meningkatkan keterampilan merawat luka ringan dan membangun minat siswa tunagrahita dalam belajar merawat luka ringan.

\section{Saran}

Adapun saran untuk sebaiknya menyiapkan materi untuk penjelasan awal dan menunjukkan peralatan $\mathrm{P} 3 \mathrm{~K}$ dengan benda konkrit sebelum menggunakan media. Diharapkan media ini dapat membantu guru untuk mengajarkan materi bina diri merawat luka ringan agar lebih menarik dan menyenangkan.

\section{DAFTAR PUSTAKA}

Apriyanto, N. (2012). Seluk-Beluk Tunagrahita dan Strategi Pembelajarannya. Yogyakarta. Javalitera.

Arikunto, S. (2013). Prosedur Penelitian Suatu Pendekatan Praktik. Jakarta: PT. Rineka Cipta

Arsyad, A. (2009). Media Pembelajaran. Jakarta: PT RajaGrafindo Persada

Basuni, M. (2012). Pembelajaran Bina Diri Pada Anak Tunagrahita Ringan. JPK (Jurnal Pendidikan Khusus), 9(1). https://journal.uny.ac.id/index.php/ ipk/article/download/6725/5780. Diakses pada tanggal 23 April 2019.

Caryoto \& Meimulyani, Y.(2013). Media Pembelajaran Adaptif. Jakarta. PT Luxima Metro Media

Ramadhani, S., \& Sudarsini, S. (2018). Efektifitas Media Quiet Book Dalam Meningkatkan Keterampilan Memakai Baju Berkancing Bagi Tunagrahita Ringan Kelas II. Jurnal ORTOPEDAGOGIA, 4(1), 12-16. http://journal2.um.ac.id/index.php/jo/ article/download/4398/2566. Diakses__pada tanggal 3 Maret 2019

Silalahi, A. 2017. Development Research (Penelitian Pengembangan) dan Research \& Development (Penelitian\&Pengembangan) Dalam Bidang Pendidikan. ResearchGate

Undang-Undang Dasar Negara Republik Indonesia. 1945. http://jdih.pom.go.id/uud1945.pdf. Diakses pada 10 Maret 2019

Indonesia, R. (2003). Undang-undang Republik Indonesia nomor 20 tahun 2003 tentang sistem pendidikan nasional. Jakarta: Pemerintah Republik Indonesia.

Widati, S. (2011). Pengajaran bina diri dan bina gerak (BDBG). http://file.upi.edu/Direktori/FIP/JUR. PEND. LUAR BIASA/195310141987032SRI WIDATI/MK BDBG/MODULrevisi.pdf 